\title{
Climate variability/change and attitude to adaptation technologies: a pilot study among selected rural farmers' communities in Nigeria
}

\author{
Ayansina Ayanlade $\mathbb{D} \cdot$ Maren Radeny $\cdot$ Akintomiwa Isaac Akin-Onigbinde
}

Published online: 20 April 2017

(C) The Author(s) 2017. This article is an open access publication

\begin{abstract}
Understanding climate variability and change is essential for designing adaptation policies and strategies to deal with the impacts of climate change on the agricultural sector. This Paper aims at assessing climate variability/change, the perception of rural farmers on climate change and preferred adaptation strategies among the farmers in some selected farming communities in Nigeria. The study thus used both meteorology data and social survey, to examine variability/change in climate and factors determining the adaptation techniques adopts by rural farmers. The results show a relatively uniform temperatures and some seasonal variations in recent years (diurnal range of temperature is about $10{ }^{\circ} \mathrm{C}$ ) but the rainfall shows much more seasonal variations. The rainfall has relatively undeviating trend from 1981 to 1996 but the trend appears to be upwards from the year 1997 to 2010. About $72.8 \%$ participants responded in the affirmative that climate is changing but there appears to be a significant relationship between the length of farming experiences and farmers' perceptions of climate change adaptation techniques. Water-related (about 53\%) and nutrient related (about 52\%) technologies appear to have a high
\end{abstract}

A. Ayanlade $(\bowtie) \cdot$ A. I. Akin-Onigbinde

Department of Geography, Obafemi Awolowo University, Ile-Ife, Nigeria

e-mail: aayanlade@oauife.edu.ng

\section{A. Ayanlade $\cdot$ M. Radeny}

CGIAR Research Programme on Climate Change,

Agriculture and Food Security (CCAFS), ILRI, Kenya preference among the farmers. The major driver that determines farmers' preference for climate change adaptation techniques is their incomes and experiences.

Keywords Changing climate $\cdot$ Local farmers · Adaptation strategies $\cdot$ Southwestern Nigeria

\section{Introduction}

Rural farmers' understanding of climate variability/ change is crucial for designing adaptation policies and strategies to deal with threats and risks of climate change in the agricultural sector. Such understanding is fundamental in Africa, since climate is the primary determinant of agricultural effectiveness, and changes in climate have pronounced impacts, not only on the agricultural sector but also on other sectors. Studies have shown that climate change and extreme climatic events pose great threats to agricultural production, food security, community health, natural resources, biodiversity, and water availability (IPCC 2013; Costello et al. 2009; Dube et al. 2016). Similarly, projections from the Intergovernmental Panel on Climate Change (IPCC 2013) have indicated similarly that the impacts of climate change would be greater on socioeconomic development and agriculture which plays much more prominent roles in food production in Africa. The projected changes in climate are likely to affect crop cultivation and yield in most part of Africa. Based on ealier studies and IPCC reports, it is 
clear that the reality of climate change and the ways in which it affects agriculture cannot be ignored (Adams et al. 1998; Christensen et al. 2007; Fernandez et al. 2007; Torquebiau et al. 2016). Other studies have shown that Sub-Saharan Africa is likely to be more vulnerable to climate change than other part of the world, not only because the economy depends on rainfed agriculture, but also the difficult challenges of poverty, high proportion of malnourished populations, low infrastructural and technological development (Niang et al. 2008; Ericksen et al. 2011; Nelson et al. 2014; Bradshaw et al. 2004). For example, a study by Ericksen et al. (2011) described African region as climate change "hotspots" due to the projected impact of climate change, as coping capacity is restricted by poverty in this part of the world. Extreme climate events such as drought, flooding, and extreme temperatures may to occur in future, with increasing frequency and intensity which some African countries might not be able to cope.

On the other hand, agriculture has a fundamental role in African economy, as the main source of income for most rural communities in the region and as the main source of foreign revenue for the majority of African countries. Scientists have been greatly concerned, about the potential impacts of climate change on the agricultural sector in this part of the world. Consequently, several attempts have been made to study the impacts, adaptation strategies and how to mitigate of climate change in relation to agricultural sectors in both global and local scales. This is because the relationship between climate and agriculture is a complex one, with several feedback loops and causal relationships. For instance, a study by Bradshaw et al. (2004) examined the adoption of crop diversification in Canadian prairie agriculture for the period between 1994 and 2002, weighing its strengths and limitations for risk management. The results of the study showed that individual farmers have undergone specialization in their cropping patterns since 1994. The study established that farmers were somehow coping with climatic risks and the trend is unlikely to change in the immediate future, regardless of expected climate change and known risk-reducing benefits of crop diversification. In Nigeria, like many other Africa countries, long-term adaptive measures have been identified in the national communications to the United Nations Framework Convention on Climate Change. Some of these countries have identified emergency measures for adaptation in their National Adaptation Programmes of Action (NAPAs), which focus on agriculture, food security, and water resources management. Many of the measures have not yet been fully implemented; leaving many farmers without a sound understanding of the challenges facing agricultural production, from climate change. These reveal that African countries are likely to be more severely affected because of their lack of adaptive capacity to climate change or variability (Kandji et al. 2006; Mertz et al. 2009). Notwithstanding, what is obvious from literature is that farmers' understanding and adaptation to climate change is imperative to ensure food security and to protect the livelihoods of the poor. Therefore, the study aims at investigating variation and change in climate, the perception, knowledge level, attitudes, and understanding of farmers regarding climate change in some farming communities in the Southwestern Nigeria. The study is based on the hypothesis that adaptation as a response to climate change is facilitated by the perceptions, level farming experience and income of farmers. An understanding of the current level of knowledge, attitudes, and perceptions of farmers serve as an indicator of how well informed they are about climate change and how well-positioned they are to adopt climate change adaptation methods.

Conceptual framework to understand climate change impacts and adaptation

Many conceptual theories have been developed to understand climate change impacts and adaptation methods. The majority of earlier studies gave typical disagreement about the appropriate concept for climate change impacts, risk, vulnerability, adaption and mitigation (Morton 2007; Owusu et al. 2015; Jethi et al. 2016). Previous conceptual frameworks on climate change impacts, vulnerability and adaption were based on a variety of characterizations and assumptions. Foremost of these are biogeophysical and social dynamics. Biogeophysical dynamics is based on the definition of impacts, vulnerability and adaption of biological, geochemical, and physical environmental systems, while social dynamics is based on the social, economic and political systems. Social dynamics involves the debate on climate change impacts, vulnerability, and adaptation in relations to changes in technological and innovation 
development, population structures, financial institutions and political body.

Frameworks developed my Morton (2007) and Owusu et al. (2015) were adopted in this study. Conceptual framework by Morton (2007) was modified by Owusu et al. (2015) and the framework explained climatic and non-climatic stress resulting from climate change, with its impacts on smallholder farmers. Part of climatic stresses identified in this framework includes droughts while non-climatic stress included those from market failures and prevalence of diseases affecting the farmers. This framework further distinguished institutional constraints from non-climatic stresses, though the effects of the three distinguished stresses on smallholder farmers' vulnerability depend on their sensitivity and resilience capacities. This assumption is established on community-based adaptation framework. The concept of community-based adaptation is founded on the premise that climate change adaptation methods/processes should be guided and based on the communities' needs, expertise, priorities, and adaptation capacities (Jethi et al. 2016; Kirkby et al. 2015). The conceptual framework for the present study is, therefore, based on the hypothesis that climate change impacts assessment and adaptation strategies should be focused on the communities capabilities. What is obvious from literature is that farmers' adaptation methods depend on social and economic status of the individual farmers and communities orientations. This study is based, therefore, on the hypothesis that climate change adaptation should be oriented to increase communities' welfares and capabilities to cope with climate change.

\section{Study area and methods}

Study area

The study area is located in Osun state of Nigeria. Seven farming communities were used in the study. Akinlalu, Faforijin, Edunabon, Erefe, Gbongan, Moro and Odemuyiwa (Fig. 1), situated in different Local Government Authority. The region is within rainforest ecological zone of Nigeria with bimodal rainfall patterns of approximately $1300 \mathrm{~mm}$ rainfall during the peak periods of the rainy season. The temperature

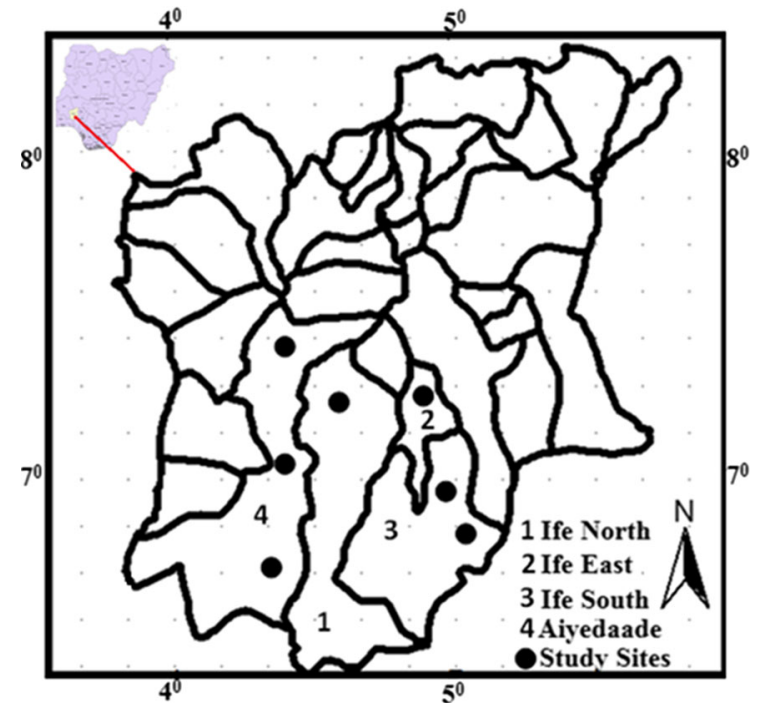

Fig. 1 Study area showing selected sites in local government areas in Osun state

in the region of the country is relatively uniform with mean monthly minimum temperature ranges from 20 to $22{ }^{\circ} \mathrm{C}$ (Ojo 1977; Ileoje 2001; Odekunle 2006). The geomorphological nature of the area is underlain by metamorphic rocks with an undulating terrain. This region is characterized by two soil types, with deep clay soils on the upper slopes and sandy soils on the lower parts. In general, the soils in this part of Nigeria are categorized as tropical red soils associated with basement complex. A study by Adejuwon and Ekanade (1988) has earlier reported that the most significant category of soils in these communities is the Itagunmodi series, which is well known for its prominence in cocoa cultivation. Soils belonging to this series are the best cocoa soil in southwestern Nigeria. The region is within rainforest zone, thus, the majority of people in this region engage in farming. The rainforest is a source of valuable timber and much of the zones that constituted the forest have been cleared to cultivate perennial and annual food crops. A Larger percentage of the population in the Southwestern region of Nigeria lives in rural areas and engaged in agricultural activities for their livelihood, thus forms agrarian societies. The area can be divided into two sub-ecological zones: The dense rainforest of the wetter southeast and the northern part with dry forest; containing a greater portion of deciduous trees (Adejuwon and Ekanade 1988). 


\section{Methods}

The study used both quantitative and qualitative datasets. Quantitative data derived from climatic records and questionnaires survey, while the qualitative dataset was derived from interviews. Daily, monthly and annual rainfall and temperature (minimum and maximum) data used in this study were obtained from the archive of the Nigerian Meteorological Agency (NMA), Lagos. The temporal resolution is from 1961 to 2013 for Oshogbo, a closest meteorological station to all the study sites. Averages of the monthly and total annual rainfall and temperature were calculated for the study area to show the rainfall variability and minimum/maximum temperature. In this study, C2 paleoclimatology software was used to analysis the climate data. Weighted averaging, partial least squares and maximum likelihood regression and calibration (ML) were calculated. A multiproxy stratigraphic diagram was employed, which allow us to plot variations in climatic data recorded at different years intervals. To achieve the objectives outlined in this study, social field survey was conducted using a structured questionnaire. Despite intent to make generalizations about awareness and perception of farmers regarding climate change in the entire Southwestern region of Nigeria, it is neither expedient nor realistic to interview all the farmers in this region. Consequently, farmers interviewed were selected at random within the study sites. In each community, some farmsteads were selected for the survey and data was obtained through questionnaires and one-on-one interview of farmers, conducted in the year 2012, 2013 and 2014. A team of research assistants was hired to administer the questionnaires, due to the spread of the communities. Care was taken to interview individuals who had been farmers for periods longer than 10 years as they were in a better position to identify and appreciate long-term trends and changes in weather patterns in their locations. Those that participated in questionnaires survey were not interviewed in order to avoid data redundancy. The information collected from the farmers includes the demographics characteristics of farmers, the crops they cultivate, and their perceived changes in climate, climate change impacts they have experienced over time. Their perceptions regarding variations in climate were assessed, adaptation strategies they have employed to mitigate the effects of climate change, and their willingness to pay for certain adaptation measures to bolster their crop yield.

There were challenges encountered during questionnaires administration. One of these challenges was the fact that a vast majority of the farmers were inexpert in climate science and this caused a communication gap between the interviewers and the respondents. Hence, the questionnaire had to be translated into the local language and key terms were explained to them in detail. The first step taken was to write the survey in a way that is readable to the respondents. This then facilitated an easier questionnaire administration exercise. Besides, some of the respondents were not eager to speak at length, demanding for money, without this, they show no interest and see the exercise as "wasting time talking". The interview questions were the subset of the questions asked in the questionnaire. A number of farmers were also restrained from speaking plainly about the perceived rainfall. Some made statements such as "only God knows what time is best for the onset of rainfall" and "only God dictates time for rain". Some refused to state in explicit, what they perceived as irregularities in onset and duration of the dry and rainy seasons. The data gathered from the interview were transcribed for easy analysis and interpretation while quantitative data was analyzed using statistical techniques available in SPSS. Detailed descriptive statistics was employed to explore data and describe the nature of the data sets while correlation analysis was carried out to assess the relationship between the length of farming experiences, incomes and the climate change perceptions. Pearson's product-moment correlation values (R2) were used to assess these relationships.

The farmers' preference for selected adaptation technologies and willingness-to-pay component was assessed, using the preference technique method (Merino-Castello 2003; Taneja et al. 2014). The stated preference technique, according to Taneja et al. (2014), involves the use of a rating and scoring system (Table 1) where a score of 0 translates to no preference, 1 means low preference, 2 means medium and 3 means high preference. The adaptation technologies selected by rural farmer in this study include (1) waterrelated technologies such as rainwater management, irrigation, (2) nutrient related technologies such as manure, leaf colour charts, fertilizers (3) weatherrelated technologies such as crop insurance and weather advisories and (4) plant engineering 
Table 1 Evaluation of farmers' preferences by scoring method. Adapted from Taneja et al. (2014)

\begin{tabular}{llc}
\hline Rating scale & Level of preference & Ranking scale (\%) \\
\hline 0 & Zero & $0-25$ \\
1 & Low & $25-50$ \\
2 & Medium & $50-75$ \\
3 & High & $75-100$ \\
\hline
\end{tabular}

technologies such as tolerant and drought resistant varieties. The farmers were presented with different scenarios and asked to rate these scenarios individually (Table 1). The ranking was performed in order to give an idea of the level of receptivity of the farmer to applying climate change adaptation technologies.

\section{Results}

Farmers' awareness of climate change and its impacts

There appears to be relatively uniform temperatures and small seasonal variations, in recent years but the rainfall shows much more seasonal variations (Fig. 2), though, the monthly temperature analysis shows that the minimum temperatures during dry season appear warmer than normal in recent years. Generally, the mean temperatures appear higher in recent years compared to the 1961-2000. The mean annual rainfall is bimodal in nature, at $1400 \mathrm{~mm}$ with peaks in July and September. The results largely show that rainfall has fluctuated at different period of the year, thus there are inter-annual variability in rainfall. However, there are gradual upward trends in rainfall patterns but much more observable from the year 1997 to 2010. The rainfall has relatively undeviating trend from 1981 to 1996 but the trend appears to be upwards from the year 1997 to 2010. Although, the decadal mean rainfall analysis show that the mean rainfall has decreased in recent years, much more in the month of March, May, September and October. Climatically, the study area is unlike other parts of the country in terms of rainfall and temperature. The mean minimum temperature ranges from 20 to $22{ }^{\circ} \mathrm{C}$ while the mean maximum for the hottest months is $32.6^{\circ} \mathrm{C}$ (Fig. 2). The diurnal range of temperature is low (about $10^{\circ} \mathrm{C}$ ) and the relative humidity is high. The major reason for this climatic uniqueness of the study area is obvious. The study sites ae located in tropical humid climate. The region experiences two seasons: the rainy season (April-October) and the dry season (NovemberMarch). The climate of the study area is influenced by the movement of three main wind currents: the Tropical Maritime (mT) air mass, the Tropical Continental (cT) air mass, and the Equatorial Easterlies (Ojo 1977; McGregor and Nieuwolt 1998). The two air masses usually meet alongside a slanting surface called the inter-tropical discontinuity (ITD). McGregor and Nieuwolt (1998) had already noted that temperatures are not a critical factor in tropical agriculture and that the choice of suitable crops is basically in relation to rainfall. Though the annual temperature in the area shows a relative increased in recent years, the rainfall annual values and variability appeared much more varied from each year (Fig. 2).

What is obvious from questionnaire analysis is that the majority of farmers note changes in the patterns of rainfall and temperature. A good proportion of the respondents has been engaged in agriculture for a significant amount of years, which is enough to enable them to appreciate the change in climate over time. From Table 2, it can be seen that the majority of the farmers had over 5 years' farming experience while only a few of the respondents had 1-5 years of farming experience. Based on farming experiences, it was easy to examine the adaptation strategies employed by the farmers, their interest in other adaptation strategies, and an assessment of the willingness of these farmers to pay for access to those adaptation strategies. Therefore, the farming experience was used to analyse of their perception, knowledge level, attitudes, and understanding regarding climate change in the selected communities. The results also showed that the mainstreams of the rural farmers $(73.3 \%)$ are male, while only $26.7 \%$ are female. These values suggest gender disparity in farming activities in the Southwestern Nigeria, in that more males engage in farming activities than females. Out of this proportion, a majority of them have a relatively underprivileged in term of education, with majority of hold primary and secondary school certificates, only a few of them have undergone some tertiary education (Table 2).

However, the majority of the farmers live below the poverty level with the distribution of the monthly income of the respondents show higher proportions of 
Fig. 2 Multi-proxy stratigraphy for precipitation and temperature in the study area

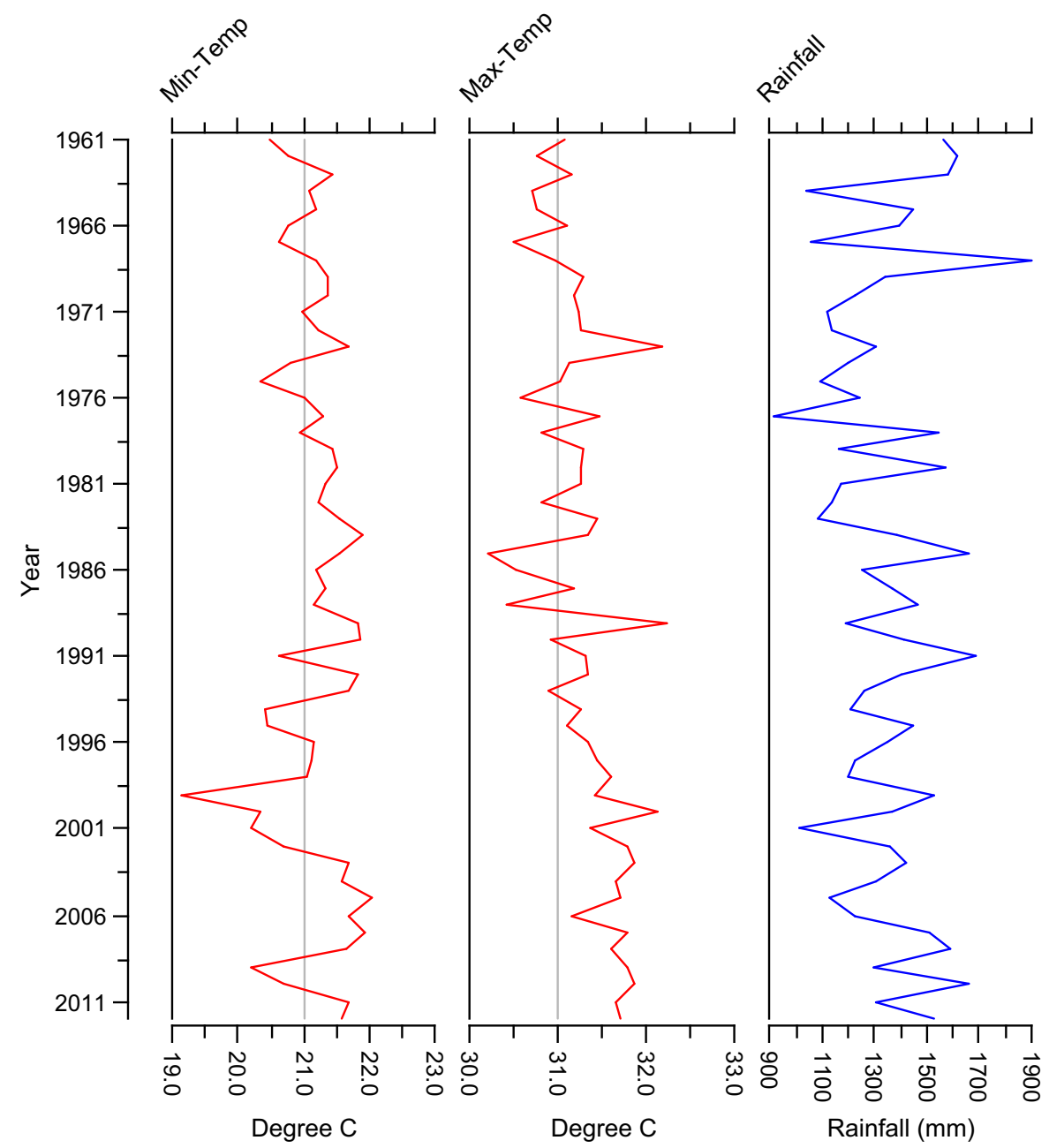

farmers' monthly incomes $<\$ 100$ (Fig. 3). The Chi square values $(\mathrm{Chi}=34.5 @ P<0.05)$ implies that level of farmers' monthly incomes is significantly determining the adaptation strategies employed by the farmers, their interest in other adaptation strategies, and the willingness of these farmers to pay for access to those adaptation strategies (Fig. 3). Table 3 shows the relative proportions of farmers in each age range and their perception of climate change. In all age range, a majority of farmers indicated that they had indeed noticed climate change. All farmers within the aged of 50 and above indicated that they had observed climate change. Also The Chi square values $($ Chi $=80.053 @ P<0.05)$ implies that age and years of farming experiences determine the adaptation strategies employed by the farmers, their interest in other adaptation strategies, and the willingness of these farmers to pay for access to those adaptation strategies (Table 3). When asked if they had noticed a change in the typical start and end date of the rainy season, many of the rural farmers answered "yes", while only a few answered "no" and some expressed uncertainty (Table 3). These results were validated through the interview when many of the farmers said that they have noticed changes in typical start and end of rain season. It is also obvious from the interview that a vast majority of farmers aware of climate change, as they said that they notice "more erratic rainfall patterns and risen temperatures". The result from interview moreover illustrates that the perception of the farmer in term of climate change varies, $72.8 \%$ of the farmers responded in the affirmative, $14.9 \%$ responded in the negative while $12.3 \%$ expressed uncertainty. 
Table 2 Respondents' characteristics according to socio-demographic variables. Source: Survey data, 2015

\begin{tabular}{|c|c|c|}
\hline Socio-economic variable & Frequency & $\%$ \\
\hline \multicolumn{3}{|l|}{ Age } \\
\hline $21-30$ & 29 & 25.2 \\
\hline $31-40$ & 49 & 42.6 \\
\hline $41-50$ & 28 & 24.3 \\
\hline $51+$ & 9 & 7.8 \\
\hline \multicolumn{3}{|l|}{ Gender } \\
\hline Male & 88 & 73.3 \\
\hline Female & 32 & 26.7 \\
\hline \multicolumn{3}{|l|}{ Level of education } \\
\hline Primary & 39 & 32.2 \\
\hline Secondary & 48 & 39.7 \\
\hline Tertiary & 34 & 28.1 \\
\hline \multicolumn{3}{|c|}{ Length of farming experience (years) } \\
\hline $1-5$ & 7 & 5.7 \\
\hline $6-10$ & 39 & 32.0 \\
\hline $11-15$ & 25 & 20.5 \\
\hline$>15$ & 51 & 41.8 \\
\hline \multicolumn{3}{|l|}{ Average monthly income } \\
\hline$<\mathrm{N} 20,000$ & 37 & 32.2 \\
\hline $\mathrm{N} 20,000-\mathrm{N} 50,000$ & 52 & 45.2 \\
\hline N50,000-100,000 & 12 & 10.4 \\
\hline$>\mathrm{N} 100,000$ & 14 & 12.2 \\
\hline
\end{tabular}

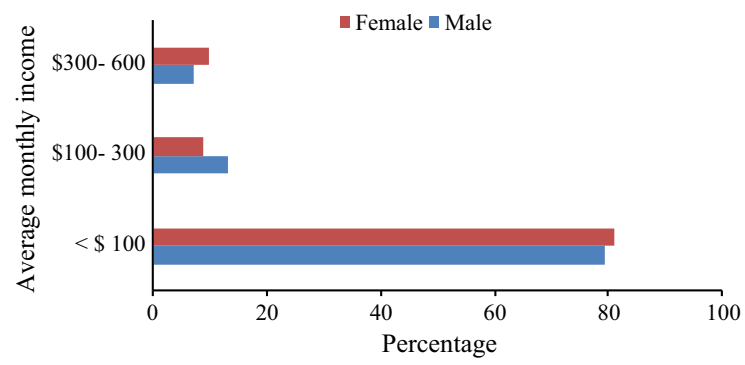

Fig. 3 Average monthly incomes with gender of respondents

As for the adaption to climate change and extreme weather events, the result shows that the majority of the farmers engaged in new planting pattern, with adjustment of the planting date to the climatic events. Table 4 illustrations the responses of the participants when asked the questions about how they cope with the effects of changing climatic on their farming practices. Several of farmers indicated that they are coping by using new planting pattern; some engaged in irrigation methods during prolong dry spells, new
Table 3 Responses to the question "Have you noticed Climate Change" cross tabulated with age of respondents

\begin{tabular}{lllcl}
\hline Age range $(\%)$ & Yes & No & Not sure & Total \\
\hline $21-30$ & 78.57 & 7.14 & 14.29 & 100 \\
$31-40$ & 71.43 & 18.36 & 10.2 & 100 \\
$41-50$ & 68.18 & 22.73 & 9.09 & 100 \\
$50+$ & 87.5 & 0 & 12.5 & 100 \\
\hline Chi $=80.053$ at 0.05 & & &
\end{tabular}

Table 4 Responses to the question "How do you cope with climate change?"

\begin{tabular}{lcc}
\hline Coping mechanism & Frequency & Percentage \\
\hline New planting pattern & 42 & 35.0 \\
Irrigation & 31 & 26.5 \\
New crop hybrid & 25 & 21.4 \\
New agricultural practice & 20 & 17.1 \\
Total & 117 & 100.0 \\
\hline
\end{tabular}

crop hybrid and selected spraying (Table 4). The results from interview show that the range of adaptation methods employed by the farmers is limited by the extent of the farmers' experience, income, and access to extension services. This is also apparent in Fig. 4 which shows the distribution of the sources fund to farmers, for cushioning agricultural losses resulting from climate change. About $7 \%$ respondents stated that they received support from the government while the majority of the farmers indicated that they rely on personal savings, funds from cooperative societies, support from friends and family as their means of coping with crop losses due to climate change. Furthermore, during the interview, the vast majority of respondents stated that they had "received no financial support from the government during agricultural losses" resulting from climatic extreme events.

For change in rainfall and temperature patterns, the majority of the farmers have noticed a significant change in recent years. When asked if they had noticed a general temperature increase over the last 15 years. About $68.9 \%$ farmers answered "yes", $23 \%$ answered "no" while 6.6\% responded 'not sure' (Table 5). They also noticed a change in the duration of the rainy and dry seasons and their impacts on crop yield. Although, there appear to be differing opinions about current rainfall patterns as opposed to past trends. Many of the 
Fig. 4 Sources of financial support in event of crop failure

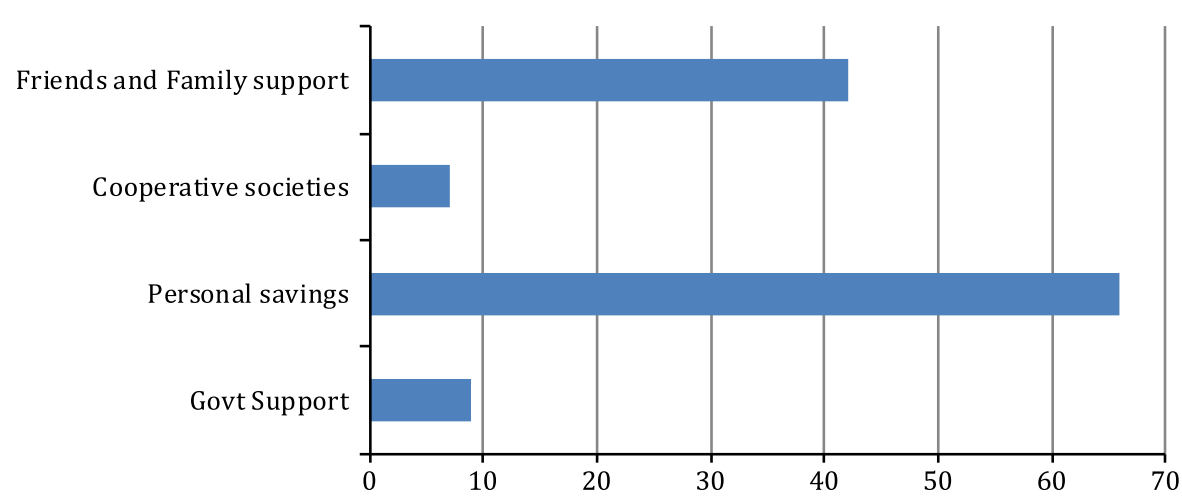

rural farmers reported a delay in onset of rainfall, early stop of rainfall, high variability in rainfall patterns and some year they noted the earlier start of rainfall (Table 5). During the interview, the farmers reported that changes in climate have high impacts on their crops when they asked the question of if the perceived temperature increase and change in rainfall patterns have impacts on the yield of their crops. A Large number of the cocoa farmers noted the climate change impacts on their crops. Figure 4 shows the number of respondents who indicated that climate change has a perceivable impact on their crop production and crop health; and the respective crops in question. On the other extreme, rubber and vegetable farmers indicated the little magnitude of impact. This result is not surprising since the majority of rural farmers in the study sites are cash crops farmers who engaged cocoa plantation (Fig. 5).

Farmers' adaptation technology preference

From Table 6 and Fig. 6, it is obvious that most of the respondents indicated a medium to a high preference for

Table 5 Notice of change in climate, farmers' responses

\begin{tabular}{lll}
\hline & Frequency & Percentage \\
\hline Rainfall patterns & & \\
Delay in onset of rainfall & 21 & 20.0 \\
Early stop of rainfall & 16 & 15.2 \\
High variability of rainfall & 28 & 26.7 \\
Early start of rainfall & 40 & 38.1 \\
Increase in temperature over the last 15 years & \\
Yes & 16 & 15.2 \\
No & 28 & 26.7 \\
Not sure & 40 & 38.1 \\
\hline
\end{tabular}

the proffered adaptation measures, with the strongest response coming from water-related and nutrient related adaptation technologies. Table 6 shows the adaptation measures, as indicated by the respondents in the survey. Water-related technologies appear to have a high preference but some of the respondents selected the nutrient related technologies. In general, low preference was recorded for weather related and plant engineering adaptation methods with a significant number of respondents (Fig. 6). The correlation results, in Table 7 show a significance relationship between the length of farming experience of the farmer, and: (1) farmers' perceptions of changes in temperature has affected the crop yield $\left(\mathrm{R}^{2}=19.2\right)$, (2) their tendency to rely on personal savings as support against agricultural losses inflicted by climate change $\left(\mathrm{R}^{2}=22.4\right)$, (3) their notice of a change in the end of the rain season $\left(\mathrm{R}^{2}=25.9\right)$, (4) farmers' awareness of the impact of changing climate on their crops $\left(\mathrm{R}^{2}=29.9\right)$, and (5) their interest in using technology to improve crop yield $\left(\mathrm{R}^{2}=38.1\right)$. It is apparent from the results that the length of farming experience of the farmers do not only determines farmers' awareness of the impact of changing climate on their crops, but also the adaptation strategies employed by the farmers, their interest in other adaptation strategies, and the willingness of these farmers to pay for access to those adaptation strategies (Table 7).

\section{Discussion}

The results from this study suggest that; to determine farmer's perception and climate change adaptation strategies, the length of farming experience, income and age are important factors, which help to understand the real scenarios. The results further revealed 
Fig. 5 Impact of climate change on select crops as perceived by the farmers

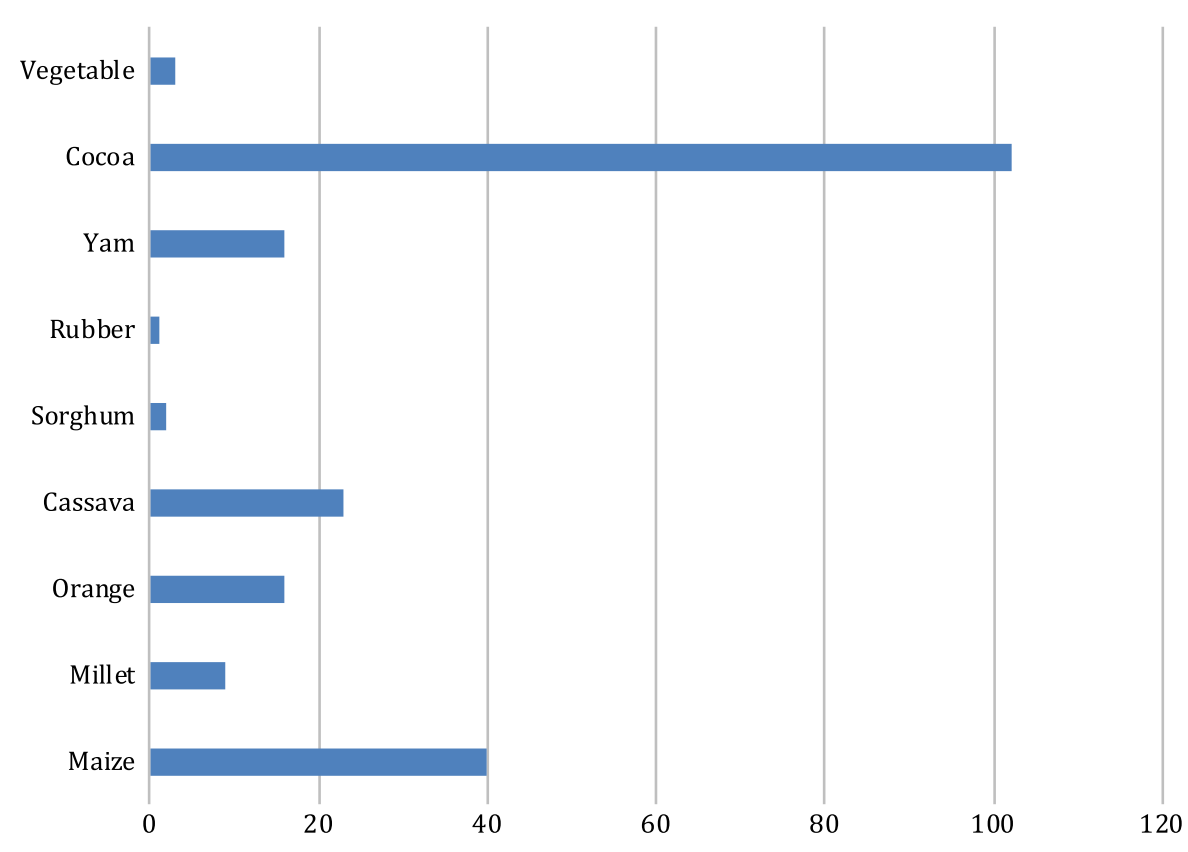

Table 6 Farmer's technology preferences

\begin{tabular}{llllrr}
\hline Scoring & A & B & C & D & Unsure \\
\hline Water related technologies & 9.90 & 48.51 & 21.78 & 9.90 & 9.91 \\
Nutrient related technologies & 11.32 & 46.23 & 23.58 & 7.55 & 11.32 \\
Weather related technologies & 11.76 & 38.24 & 19.60 & 14.71 & 15.67 \\
Plant engineering related technologies & 20.41 & 29.59 & 25.51 & 11.22 \\
\hline
\end{tabular}

'A' represents highly preferred, 'B' represents medium preference, 'C' represents low preference and 'D' represents not preferred

Fig. 6 Preferences for adaptation strategies

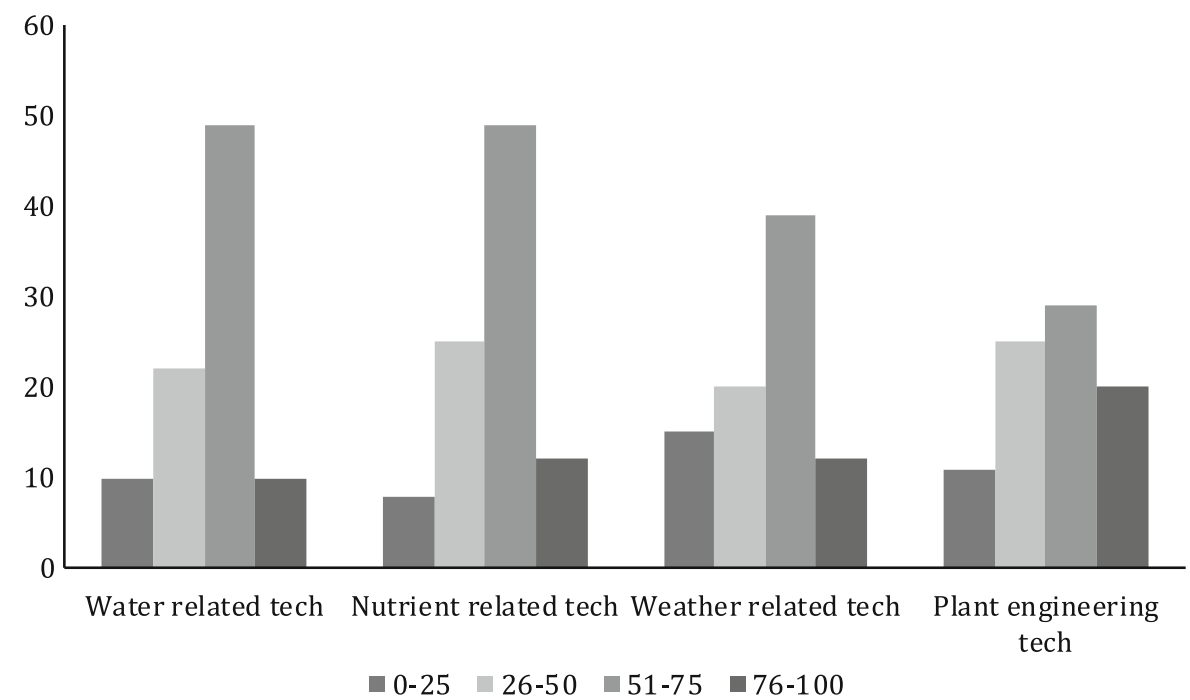


Table 7 Significant correlation between length of farming experience and other relevant variables

\begin{tabular}{ll}
\hline Significant response & $\begin{array}{l}\text { Length of farming experience } \\
\mathrm{R}^{2}\end{array}$ \\
\hline Change in temperature has affected the crop yield & $19.2^{*}$ \\
Notice of a change in the end of the rain season & $25.9 * *$ \\
Awareness of the impact of changing climate on their crops & $29.9 * *$ \\
Tendency to rely on personal savings as support & $22.4^{*}$ \\
Technology preferences for adaptation strategies & $28.1^{* *}$ \\
\hline
\end{tabular}

* Correlation is significant at the 0.05 level

** Correlation is significant at the 0.01 level

that most farmers are sensitive to climate change, and have noticed increased in temperatures and irregular onset and duration of the rainy season, which have impacts on crop production in the study area. The majority of the rural farmers are aware of the climate change, as evidenced by more irregular rainfall patterns and increased temperatures. They notice also the extreme climate events such as drought occurrence and prolong dry spells within the cropping seasons. The main finding of this study is that climate change has a profound and multifaceted impacts on agricultural practices; especially with respect to the most important climatic elements, namely rainfall and temperature. However, there still exists a vacuum in the existing literature, in terms of assessing farmers' sensitivity to climate change in Nigeria, which is the main contribution of the present study.

On the issue of assessing farmers' sensitivity to climate change, the majority of farmers claimed that climate change as the most prevalent disaster in recent years, leading to rainfall and temperature deviations thus affecting the crop yields. Previous research by Mall and Aggarwal (2002) has highlighted similar scenarios, that increase in temperature has led to a decrease in the length of the growing season and the yield of many crops. The high number of farmers indicated impacts of climate change on their cocoa, cassava, yam and maize crop (Fig. 5) confirm results obtained by previous studies (Ericksen et al. 2011; Jones and Thornton 2003; Laux et al. 2003; Mall and Aggarwal 2002). The findings from these studies show a relationship between climatic variability and crop yield, and an inverse relationship between crop output and climatic events. In the present study, however, farmers who cultivate millet, orange, sorghum, rubber and vegetables indicated climate change impacts on crop production less often (Fig. 5). Conversely, some studies (Duku et al. 2016; Laux et al. 2010; Cammarano et al. 2016; Odekunle et al. 2007; Deryng et al. 2014) have noted impacts of climate change on crop yields under rain-fed conditions. These studies discovered that the onset of the rainy season is the most important variable for crop production. In some other studies, rain was described as being less predictable and was thought to have a greater number of "false starts" leading to difficulty in identifying the correct time to begin sowing and lesser qualities than "before" (Lebel and Ali 2009; Oliver and Robertson 2013; Moron and Robertson 2014; Odekunle 2006; Maddison 2007).

Nevertheless, the findings from the present study is also in line with the results from previous studies that age, income, and other socio-economic characteristics have a significant effect on farmers' perception of climate change (Deressa et al. 2009; Bryan et al. 2009; Bradshaw et al. 2004; Davis and Ali 2014). Deressa et al. (2009) had earlier reported similar findings, on the determinants of farmers' choice of adaptation methods and perceptions of climate change in the Nile Basin of Ethiopia. Age of the household head, income, social capital, and agro-ecological settings were found to have significant effects on farmers' perceptions of climate change and choice of adaptation methods. But years of farming experiences and farmers' income level determined the choice of adaptation methods. Some studies have discovered similar results. Davis and Ali (2014) investigated climate change impact and adaptation in rural Bangladesh, using focus group discussions and key informant interviews. The study concluded that climate change is indeed affecting 
agricultural production. Maddison (2007) reported on perceptions of climate change in 11 African countries and showed that a significant number of farmers believe that temperature has already increased, and that precipitation has declined. The present study further revealed that farmers with more experience were more likely to notice changes in climatic conditions. The study also detailed that farmers' experience, access to free extension services and markets are important determinants of adaptation. Bradshaw et al. (2004) examined the adoption of crop diversification in Canadian prairie agriculture for the period between 1994 and 2002, weighing its strengths and limitations for risk management; including climatic risks. Results showed that individual farmers have undergone specialization in their cropping patterns since 1994 and that that trend was unlikely to change in the immediate future, regardless of expected climate change and known risk-reducing benefits of crop diversification. What is obvious from the present study, as confirmed by previous studies, is the close link between climate change adaptation and mitigation in the agricultural sector. Studies have posited that many of the adaptation practices such as mixed cropping, green manure, agroforestry and improved rangeland management sequester carbon and recent adaptation method listed by recent studies, are essential for farmers in Africa to cope with change in climate. Though good agricultural management practices have the potential for poverty reduction, environment, and climate protection, the present study further asserted that for climate change adaptation methods to be effective, local knowledge should be used in conjunction with scientific knowledge systems.

\section{Conclusions}

In the present study, the perception, knowledge level and attitudes of farmers to climate change adaptation methods were investigated in some selected communities in the Osun state of Nigeria. The study focuses on understanding of climate variability/change, farmers understanding of how it affects their crop production and what measures they can take to reduce its impact on their crop yield. The farmers participated in this study dependent on the favourable timing of weather seasons and rainwater for watering of plants.
The results from this study indicate strong impacts of climate variability/chnage on crop yield; primarily because farming activities in this region is often small scale and are rain-fed subsistence agriculture. The key findings from this study are that: (1) length of farming experiences determine the level of awareness and sensitivity that farmers have about climate change; (2) the length of farming experiences also informs the level farmers understanding climate change and the strategies they implement to cope with climate change and extreme weather events. The findings from the present study suggest that most farmers are sensitive to climate variability/change, and they noticed increased in temperatures and irregular onset and duration of the rainy season. They perceived that these exert considerable impacts on crop production in the study area. These results confirm the likelihood of the conclusion that climate change will likely have mostly negative effects on agriculture in developing countries such as Nigeria (Banik et al. 2015; IPCC 2014; Havlík et al. 2015; Mereu et al. 2015). The major finding of this study is that majority of farmers received little support from the government; this puts farmers in a difficult situation and forces them to rely on savings and intervention from friends and family during crop failure.

There is a need, therefore, for agricultural reformation. This will include better government policies that provide more financial aid to farmers during and after crop loss due to climate change and other extreme climatic events. Farmers need this kind of supports to cope with crop losses caused by climate change. This resilience can be built up by the provision of insurance plans for farmers which are tailored to their needs. There is a need to improve accessibility to government loans and subsidies, especially, during extreme weather events. Above all, farmers should be encouraged to plant drought resistant varieties of crops in areas which are susceptible to water shortages and dry spells. This can be achieved by improving local research which can lead to the breed of appropriate drought resistant seed varieties. Locality-specific adaptation strategies need to be developed to breed drought-resistant varieties of crops, which can cope with extreme weather events in the tropical region. There is no doubt that development of drought resistant varieties of crops is a promising method of adaptation to climate change. 
Acknowledgements This work was a pilot study of a research project funded and supported by the Department for International Development (DFID) of the United Kingdom (UK) through The Climate Impact Research Capacity and Leadership Enhancement in Sub-Saharan Africa programme (CIRCLE), Grant Cohort 2. The authors thank the anonymous reviewers for their suggestions which remarkably improved the contents of the manuscript.

\section{Compliance with ethical standards}

Conflict of interest The authors declare that they have no competing interests.

Open Access This article is distributed under the terms of the Creative Commons Attribution 4.0 International License (http:// creativecommons.org/licenses/by/4.0/), which permits unrestricted use, distribution, and reproduction in any medium, provided you give appropriate credit to the original author(s) and the source, provide a link to the Creative Commons license, and indicate if changes were made.

\section{References}

Adams, R. M., Hurd, B. H., Lenhart, S., et al. (1998). Effects of global climate change on agriculture: An interpretative review. Climate Research, 11(1), 19-30.

Adejuwon, J., \& Ekanade, O. (1988). A comparison of soil properties under different landuse types in a part of the Nigerian cocoa belt. CATENA, 15(4), 319-331.

Banik, S., Pankaj, P., Naskar, S. (2015). Climate change: Impacts on livestock diversity in tropical countries. In P. K. Malik, R. Bhatta, J. Takahashi, R. Kohn \& C. S. Prasad (Eds.), Livestock production and climate change (Vol. 6, p. 162).

Bradshaw, B., Dolan, H., \& Smit, B. (2004). Farm-level adaptation to climatic variability and change: Crop diversification in the Canadian prairies. Climatic Change, 67(1), 119-141.

Bryan, E., Deressa, T. T., Gbetibouo, G. A., et al. (2009). Adaptation to climate change in Ethiopia and South Africa: Options and constraints. Environmental Science \& Policy, 12(4), 413-426.

Cammarano, D., Zierden, D., Stefanova, L., et al. (2016). Using historical climate observations to understand future climate change crop yield impacts in the Southeastern US. Climatic Change, 134(1), 311-326.

Christensen, J., Hewitson, B., Busuioc, A., et al. (2007). Regional climate projections [Book Section] Climate change 2007: The physical science basis. In S. Solomon, D. Qin, M. Manning, Z. Chen, M. Marquis, K. B. Averyt, M. Tignor \& M. L. Miller (Eds.) Contribution of Working Group I to the Fourth Assessment Report of the Intergovernmental Panel on Climate Change. Cambridge: Cambridge University Press.

Costello, A., Abbas, M., Allen, A., et al. (2009). Managing the health effects of climate change. The Lancet, 373(9676), 1693-1733.
Davis, P., \& Ali, S. (2014). Exploring local perceptions of climate change impact and adaptation in rural Bangladesh. IFPRI Discussion Paper 01322. Washington, DC: International Food Policy Research Institute.

Deressa, T. T., Hassan, R. M., Ringler, C., et al. (2009). Determinants of farmers' choice of adaptation methods to climate change in the Nile Basin of Ethiopia. Global Environmental Change, 19(2), 248-255.

Deryng, D., Conway, D., Ramankutty, N., et al. (2014). Global crop yield response to extreme heat stress under multiple climate change futures. Environmental Research Letters, 9(3), 034011.

Dube, T., Moyo, P., Ncube, M., et al. (2016). The impact of climate change on agro-ecological based livelihoods in Africa: A review. Journal of Sustainable Development, 9(1), 256-267.

Duku, C., Sparks, A. H., \& Zwart, S. J. (2016). Spatial modelling of rice yield losses in Tanzania due to bacterial leaf blight and leaf blast in a changing climate. Climatic Change, 135(3), 569-583.

Ericksen, P., Thornton, P., Notenbaert, A., Cramer, L., Jones, P., \& Herrero, M. (2011). Mapping hotspots of climate change and food insecurity in the global tropics. In CGIAR research program on Climate Change, Agriculture and Food Security (CCAFS). Copenhagen, Denmark.

Fernandez, M., Rosegrant, M., Sinha, A., et al. (2007). Looking into the future for agriculture and AKST (agriculture, knowledge, science and technology) Chapter 5. International Assessment of Agricultural Science and Technology Development. World Bank, Washington, DC.

Havlík, P., Valin, H., Gusti, M., et al. (2015). Climate change impacts and mitigation in the developing world: An integrated assessment of the agriculture and forestry sectors. World bank policy research working paper.

Ileoje, N. (2001). A New geography of Nigeria, new revised edition. Longman Publishers: Ibadan.

IPCC. (2013). The physical science basis: Working group I contribution to the fifth assessment report of the intergovernmental panel on climate change (Vol. 1, pp. 535-531). New York: Cambridge University Press.

IPCC. (2014). Climate change 2014-impacts, adaptation and vulnerability: Regional aspects. Cambridge: Cambridge University Press.

Jethi, R., Joshi, K., \& Chandra, N. (2016). Toward climate change and community-based adaptation-mitigation strategies in hill agriculture. In Conservation agriculture (pp. 185-202). Singapore: Springer.

Jones, P. G., \& Thornton, P. K. (2003). The potential impacts of climate change on maize production in Africa and Latin America in 2055. Global Environmental Change, 13(1), 51-59.

Kandji, S. T., Verchot, L., \& Mackensen, J. (2006). Climate change climate and variability in Southern Africa: Impacts and adaptation in the agricultural sector. UNEP and ICRAF.

Kirkby, P., Williams, C., \& Huq, S. (2015) A brief overview of community-based adaptation. International centre for climate change and development: Briefing paper.

Laux, P., Jäckel, G., Tingem, R. M., et al. (2010). Impact of climate change on agricultural productivity under rainfed conditions in Cameroon-A method to improve attainable 
crop yields by planting date adaptations. Agricultural and Forest Meteorology, 150(9), 1258-1271.

Laux, C., Spence, T., Kruger, C., et al. (2003). Optical diagnostics of atmospheric pressure air plasmas. Plasma Sources Science and Technology, 12(2), 125.

Lebel, T., \& Ali, A. (2009). Recent trends in the Central and Western Sahel rainfall regime (1990-2007). Journal of Hydrology, 375(1), 52-64.

Maddison, D. J. (2007). The perception of and adaptation to climate change in Africa. World bank policy research working paper.

Mall, R., \& Aggarwal, P. (2002). Climate change and rice yields in diverse agro-environments of India. I. Evaluation of impact assessment models. Climatic Change, 52(3), 315-330.

McGregor, G. R., \& Nieuwolt, S. (1998). Tropical climatology: An introduction to the climates of the low latitudes. New York: Wiley.

Mereu, V., Carboni, G., Gallo, A., et al. (2015). Impact of climate change on staple food crop production in Nigeria. Climatic Change, 132(2), 321-336.

Merino-Castello, A. (2003) Eliciting consumers preferences using stated preference discrete choice models: Contingent ranking versus choice experiment. UPF economics and business working paper.

Mertz, O., Mbow, C., Reenberg, A., et al. (2009). Farmers' perceptions of climate change and agricultural adaptation strategies in rural Sahel. Environmental Management, 43(5), 804-816.

Moron, V., \& Robertson, A. W. (2014). Interannual variability of Indian summer monsoon rainfall onset date at local scale. International Journal of Climatology, 34(4), 1050-1061.

Morton, J. F. (2007). The impact of climate change on smallholder and subsistence agriculture. Proceedings of the National Academy of Sciences, 104(50), 19680-19685.
Nelson, G. C., Mensbrugghe, D., Ahammad, H., et al. (2014). Agriculture and climate change in global scenarios: Why don't the models agree. Agricultural Economics, 45(1), 85-101.

Niang, I., Osman-Elasha, B., Githeko, A., et al. (2008) Africa climate change 2007: Impacts, adaptation and vulnerability. Contribution of working group II to the fourth assessment report of the intergovernmental panel on climate change.

Odekunle, T. (2006). Determining rainy season onset and retreat over Nigeria from precipitation amount and number of rainy days. Theoretical and Applied Climatology, 83(1), 193-201.

Odekunle, T., Orinmoogunje, I., \& Ayanlade, A. (2007). Application of GIS to assess rainfall variability impacts on crop yield in Guinean Savanna part of Nigeria. African Journal of Biotechnology, 6(18), 2100-2113.

Ojo, O. (1977). The climates of West Africa. London: Heinemann Educational Books Ltd.

Oliver, Y., \& Robertson, M. (2013). Quantifying the spatial pattern of the yield gap within a farm in a low rainfall Mediterranean climate. Field Crops Research, 150, 29-41.

Owusu, K., Obour, P. B., \& Asare-Baffour, S. (2015). Climate variability and climate change impacts on smallholder farmers in the Akuapem North District, Ghana. In Handbook of climate change adaptation (pp. 1791-1806). Berlin: Springer.

Taneja, G., Pal, B. D., Joshi, P. K., et al. (2014). Farmers preferences for climate-smart agriculture: An assessment in the Indo-Gangetic Plain. International Food Policy Research Institute.

Torquebiau, E., Berry, D., Caron, P., et al. (2016). New research perspectives to address climate challenges facing agriculture worldwide. In Climate change and agriculture worldwide (pp. 337-348). Dordrecht: Springer. 